\title{
Flowchart for non-invasive ventilation support in COVID-19 patients from a northern Italy Emergency Department
}

\author{
Daniele Privitera ${ }^{1}$ (I) $\cdot$ Laura Angaroni $^{1} \cdot$ Nicolò Capsoni $^{1} \cdot$ Elisa Forni ${ }^{1} \cdot$ Federico Pierotti ${ }^{1} \cdot$ Fabrizio Vincenti $^{1}$. \\ Andrea Bellone ${ }^{1}$
}

Received: 15 April 2020 / Accepted: 6 May 2020 / Published online: 20 May 2020

(c) Società Italiana di Medicina Interna (SIMI) 2020

\begin{abstract}
With the rapid pandemic spread of the novel coronavirus (SARS-CoV2), Emergency Departments of affected countries are facing an increasing number of patients presenting with hypoxemic respiratory failure due to coronavirus disease 2019 (COVID-19). Providing mechanical support and endotracheal intubation can be challenging due to a number of patients larger than usual, often exceeding available resources. Considering the lack of recommendations available, we developed a flowchart to standardize the first approach to patients presenting to the Emergency Department with hypoxemic respiratory failure due to COVID-19.
\end{abstract}

Keywords Continuous positive airways pressure $\cdot$ Non-invasive ventilation $\cdot$ COVID-19 Hypoxemic respiratory failure

\section{Background}

As a consequence of the rapid pandemic spread of the novel coronavirus (SARS-CoV2), and the exponential rising of patients with coronavirus disease 2019 (COVID-19), health systems of affected countries are facing an increasing number of patients presenting to Emergency Departments with hypoxemic respiratory failure. The demand of mechanical support and endotracheal intubation (ETI) is higher than normal and often exceeds available resources, with the need to rapidly expand the medical resources available.

SARS-CoV2, similar to SARS-CoV [1], causes a range of heterogeneous clinical pictures in human going from common cold to severe respiratory failure. Due to its respiratory system tropism, it can lead to diffuse alveolar damage with cellular fibro myxoid exudates, desquamation of pneumocytes, and hyaline membrane formation [2]. Emerging evidence suggests an exuberant "cytokine storm" reaction of the host with features similar to bacterial sepsis, and reports

Andrea Bellone

andrea.bellone@ospedaleniguarda.it

Daniele Privitera

danieleprivi@gmail.com

1 Dipartimento Emergenza Urgenza - Pronto Soccorso, ASST Grande Ospedale Metropolitano Niguarda, Piazza dell'Ospedale Maggiore 3, 20162 Milan, Italy high inflammatory markers like elevated C-reactive protein, D-dimer, and ferritin being able to relate to disease severity and mortality [3]. Severe disease might result in acute and progressive respiratory failure due to massive alveolar damage, till Acute Respiratory Distress Syndrome (ARDS) develops [4].

A high rate of COVID-19 patients presents with severe hypoxic respiratory failure, $19 \%$ in first data coming from China with 5\% requiring mechanical ventilation and intensive-care unit (ICU) [5]. Therefore, immediately supplemental oxygen therapy is mandatory when $\mathrm{SpO}_{2}$ levels are low $(<90 \%)$, with the aim to increase $\mathrm{SpO}_{2}$ and maintain it no higher than 96\% [6]. Evidence showed that a liberal oxygen strategy is associated with increased risk of hospital mortality in acutely ill patients [7].

They have usually a fairly normal pulmonary compliance, especially in the first phases of the disease. That indicates well-preserved lung gas volume and relatively low work of breathing prior to intubation in sharp contrast to expectations for severe ARDS. The loss of lung perfusion regulation and hypoxic vasoconstriction might play an important role in generating their severe hypoxemia. Due to preserved compliance, COVID-19 patients do not have excessively increased work of breathing and may develop "silent hypoxemia" with the risk of a rapid decline without severe symptoms complaint. 
Due to progressive alveolar damage and infiltrates, progressive alveolar collapse can develop, with a gradual distortion of lung architecture promoting collapsing of neighboring alveoli and development of atelectasic areas.

The application of a positive end expiratory pressure (PEEP) is useful for lung recruitment and to improve ventilation perfusion mismatch.

Evidence on non-invasive positive pressure ventilation (NIPPV) in acute respiratory failure (ARF) due to viral pneumonia is lacking and its use is still of uncertain benefit $[8,9]$. Data from observational studies on the use of NIPPV in Influenza A (H1N1) viral pneumonia showed a variable successful rate between 40.7 and 48\% [10-12]. Some studies reported an increased ICU mortality in patients who failed NIPPV trial compared with early invasive mechanical ventilation, whereas NIPPV success resulted in shorter hospital stay. NIPPV failure was associated with higher SOFA scores and lower P/F levels $[10,11,13]$. A high rate of NIPPV failure (92.4\%) was reported in critically ill patients with the Middle East Respiratory Syndrome (MERS) [14].

Due to the lack of Randomized-Controlled Trials, no recommendations are offered on NIPPV use in these patients, but according to data from observational studies, a cautious NIPPV trial in selected patients in a protected environment and experienced centers can be tried. An NIPPV trial could be attempted for $60 \mathrm{~min}$, being aware that a prolonged NIPPV treatment can be harmful delaying intubation and provoking large tidal volumes, injurious transpulmonary pressures, and increasing the risk of patient self-inflicted lung injury [15].

Because COVID-19 patients have often a tolerable work of breathing, they may not need much mechanical inspiratory support, but can benefit from a simply continuous positive airways pressure (CPAP). CPAP is able to deliver PEEP and to provide alveolar recruitments, avoiding excessive harmful tidal volumes, and reducing patient's high negative intrathoracic pressure swings which can increase lung injury. Due to its potential negative effects, the lowest useful PEEP should be find to avoid severe hemodynamic impairment, fluid retention, gastric insufflation, and aspiration. CPAP delivered by head helmet has been shown as safe and effective as CPAP delivered by face mask, and better tolerated for prolonged ventilation periods [16]. Moreover, with the use of a closed system and viral filters, the helmet can be reasonably safe regarding viral transmission [17].

\section{Flowchart}

Considering the lack of recommendations available in the literature, it could be useful to standardize the first approach to COVID-19 patients presenting to the Emergency
Department with hypoxemic respiratory failure, diagnosed clinically and with initial arterial blood gas test (ABG).

The flowchart which we propose here (Fig. 1) does not refer to patients presenting with an altered mental status (Kelly score $\geq 3$ ) [18], unstable hemodynamics, and/or a state of shock or impaired/ineffective respiratory mechanics (e.g., agonic breathing and thoraco-abdominal dyskinesia), who theoretically require immediate ETI.

Many COVID-19 patients present with severe hypoxemia and supplemental administration should not be delayed. The first step is $5 \mathrm{~L} / \mathrm{min}$ oxygen administration through nasal googles or face mask targeting a $\mathrm{SpO}_{2}$ level $\geq 94 \%$, starting a close vital signs' monitoring with a particular attention to respiratory rate (RR) and $\mathrm{SpO}_{2}$, which should be monitored continuously.

After this first intervention, the patient should be reassessed after 10-15 min.

If the established $\mathrm{SpO}_{2}$ target has not been quickly reached, an advanced ventilatory support, such as NIPPV or CPAP, should be started without any further delay. After the selection of patients requiring early ETI, it is crucial to define quickly the best non-invasive ventilation modality for each patient.

While preparing the equipment to start non-invasive ventilation, supplemental oxygen should be administered with a reservoir mask (till $15 \mathrm{~L} / \mathrm{min}$ ) to increase the $\mathrm{SpO}_{2}$ level to the target.

Mandatory conditions to start CPAP or NIPPV are:

- a preserved state of consciousness (Kelly Score 1 or 2)

- stable hemodynamics

- $\mathrm{RR} \geq 28 \mathrm{bpm}$.

CPAP delivered through helmet and high-flow generating devices should be started as first choice.

NIPPV should be considered alternatively to CPAP in case of lack of equipment to provide CPAP with helmet and for patients with hypercapnic respiratory failure and risk of muscular exhaustion (e.g., history of chronic obstructive pulmonary disease and neuromuscular disease). A trial should be attempted being aware that a prolonged NIPPV treatment can be harmful delaying intubation.

\section{CPAP}

In case hypoxemia does not respond to $\mathrm{O}_{2}$ supplementation, CPAP should be started. CPAP does not actively reduce patients' respiratory effort, but, through alveolar recruitment, improve respiratory compliance and improves the ventilation perfusion mismatch, reducing the degree of hypoxemia even in cases refractory to standard oxygen therapy. 


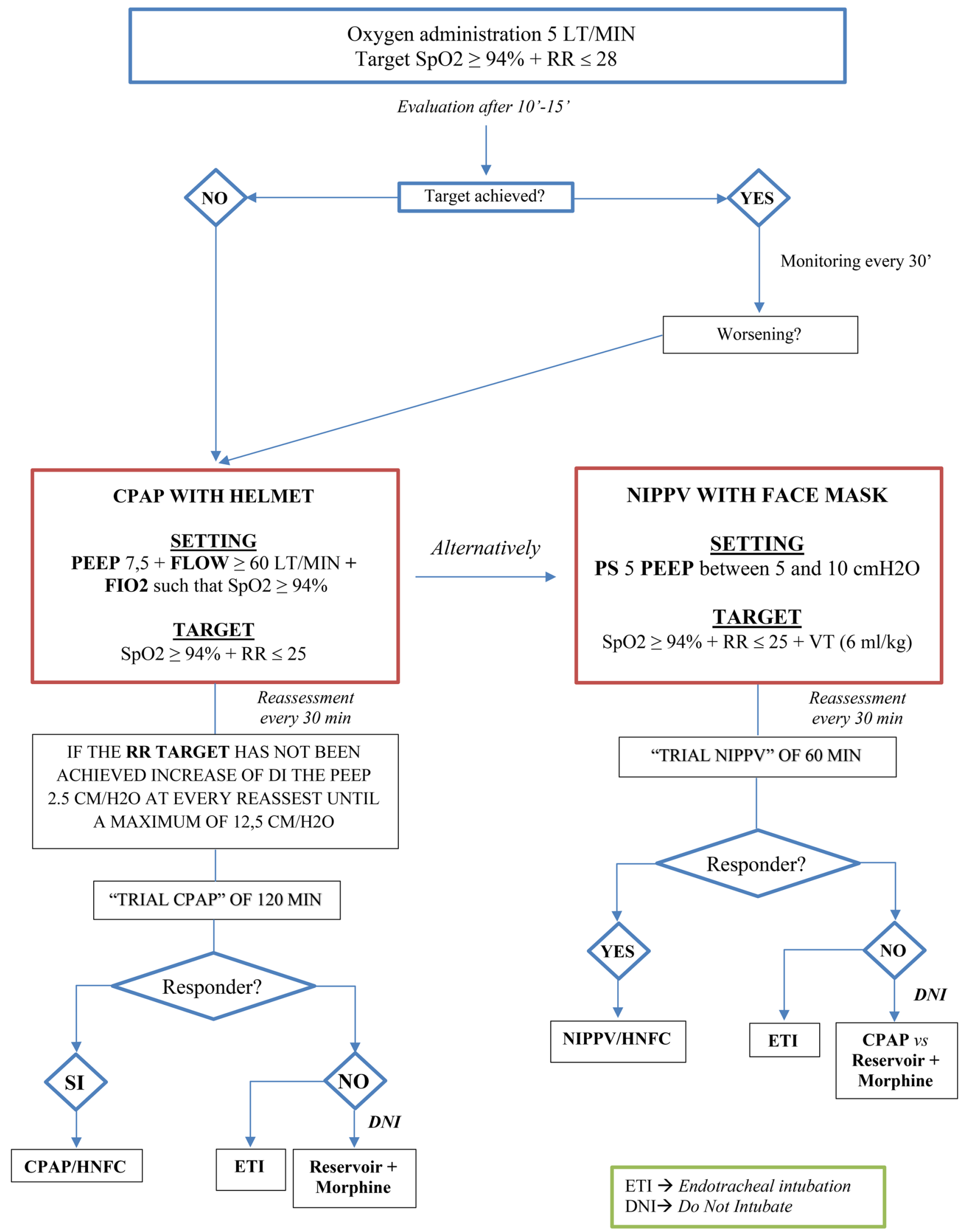

Fig. 1 COVID-19 patient support ventilation flowchart 
Given the small number of mechanical ventilators currently available, CPAP is delivered through helmet and highflow generating devices.

A CPAP trial of 120 min should be started. As the initial setting, we start with a PEEP of $7.5 \mathrm{~cm} / \mathrm{H}_{2} \mathrm{O}$ and a Flow $\geq 60 \mathrm{~L} / \mathrm{min}$, titrating the $\mathrm{FiO}_{2}$ to reach a $\mathrm{SpO}_{2} \geq 94 \%$ and an $\mathrm{RR} \leq 25 \mathrm{bpm}$. A continuous vital signs monitoring is necessary and the patient should be reassessed with all his vital signs every 30 min till the end of the trial. During every half an hour reassessment, PEEP should be increase by $2.5 \mathrm{cmH}_{2} \mathrm{O}$ up to a maximum of $12.5 \mathrm{cmH}_{2} \mathrm{O}$ in case of failure to reach the RR established target, whereas no modification of the setting is necessary if the target is reached.

If $\mathrm{SpO}_{2} \geq 94 \%$ and an $\mathrm{RR} \leq 25 \mathrm{~min}$ is reached after the 120 min trial, CPAP should be continued alternating with high-flow nasal oxygen (HFNO), maintaining continuous monitoring of vital signs.

In case of failure to reach the established targets after 120 min of CPAP trial, early ETI should be considered in patients candidates for intensive-care unit. In patients with a DNI order, the choice to continue helmet CPAP or shift to standard $\mathrm{O}_{2}$ therapy and start palliative care depends on clinician evaluation. Many DNI patients actually do not receive treatment-limitation decisions, and CPAP, if well tolerated, can still ameliorate respiratory exchanges and compliance, reducing hypoxemia and dyspnea.

\section{NIPPV}

As initial setting, we start NIPPV with a Pressure Support (PS) of $5 \mathrm{cmH}_{2} \mathrm{O}$ and a PEEP between 5 and $10 \mathrm{cmH}_{2} \mathrm{O}$, titrating the $\mathrm{FiO}_{2}$ to reach the desired $\mathrm{SpO}_{2}$.

During the trial, a careful and continuous vital signs' monitoring must be performed to early recognize any signs of clinical deterioration. A medical/nursing reassessment is required after $30 \mathrm{~min}$ and repeated at the end of the trial after 60 min. If a $\mathrm{SpO}_{2} \geq 94 \%$ and an $\mathrm{RR} \leq 25 \mathrm{bpm}$ with a low tidal volume of $6 \mathrm{~mL} / \mathrm{kg}$ predicted body weight (PBW) is reached after the $60 \mathrm{~min}$ trial, NIPPV can be continued alternating with high-flow nasal canula (HFNC). In hypercapnic patients $\mathrm{ABG}$ test should be repeated after $30 \mathrm{~min}$ to evaluate if respiratory acidosis has improved.

In case of NIPPV failure to reach the established targets, ETI should be performed in patients' candidates for intensive care. On the contrary, in patients who received a do-notintubate (DNI) order, standard $\mathrm{O}_{2}$ treatment or CPAP could be used to reduce hypoxemia and dyspnea, and starting palliative care should be considered.

Providing advanced ventilatory support requires adequate settings, the possibility of continuous vital signs monitoring, and highly competent medical and nursing staff.
Acknowledgements We would like to thank our NIV Group for their great effort, especially Annamaria Mazzone, Eugenia Rocca, Raffaela Amato, Consuelo Mocci, Gerlando Barba, Luca Conti, Riccardo Giammarrusto, Gabriele Mecca, and Sebastiana Rubanu.

\section{Compliance with ethical standards}

Conflicts of interest The authors declare that they have no conflict of interest.

Statement of human and animal rights This article does not contain any studies with human participants or animals performed by any of the authors.

Informed consent None.

\section{References}

1. McCloskey B, Heymann DL (2020) SARS to novel coronavirus - Old lessons and new lessons. Epidemiol Infect 148:1-4

2. Xu Z, Shi L, Wang Y, Zhang J, Huang L, Zhang C et al (2020) Pathological findings of COVID-19 associated with acute respiratory distress syndrome. Lancet Respir Med. 8:420-422

3. Ruan Q, Yang K, Wang W, Jiang L, Song J (2020) Clinical predictors of mortality due to COVID-19 based on an analysis of data of 150 patients from Wuhan. China. Intensive Care Med 46(5):846-848

4. Huang C, Wang Y, Li X, Ren L, Zhao J, Hu Y et al (2020) Clinical features of patients infected with 2019 novel coronavirus in Wuhan. China Lancet 395(10223):497-506

5. Wu Z, McGoogan JM (2020) Characteristics of and important lessons from the coronavirus disease 2019 (COVID-19) outbreak in China: summary of a report of 72314 cases from the Chinese Center for Disease Control and Prevention. JAMA J Am Med Assoc 2019:3-6

6. World Health Organization (2020) Clinical management of severe acute respiratory infection (SARI) when COVID-19 disease is suspected: interim guidance, 13 March 2020 (license: CC BYNC-SA 3.0 IGO). https://apps.who.int/iris/handle/10665/331446

7. Chu DK, Kim LHY, Young PJ, Zamiri N, Almenawer SA, Jaeschke R et al (2018) Mortality and morbidity in acutely ill adults treated with liberal versus conservative oxygen therapy (IOTA): a systematic review and meta-analysis. Lancet 391(10131):1693-1705

8. Rochwerg B, Brochard L, Elliott MW et al (2017) Official ERS/ ATS clinical practice guidelines: noninvasive ventilation for acute respiratory failure. Eur Respir J 50:1602426. https://doi. org/10.1183/13993003.02426-2016

9. Arabi YM, Fowler R, Hayden FG (2020) Critical care management of adults with community-acquired severe respiratory viral infection. Intensive Care Med 46(2):315-328

10. Masclans JR, Pérez M, Almirall J, Lorente L, Marqués A, Socias L et al (2013) Early non-invasive ventilation treatment for severe influenza pneumonia. Clin Microbiol Infect 19(3):249-256

11. Rodríguez A, Ferri C, Loeches IM, Díaz E, Masclans JR, Gordo F et al (2017) Risk factors for noninvasive ventilation failure in critically ill subjects with confirmed influenza infection. Respir Care 62(10):1307-1315

12. Nicolini A, Tonveronachi E, Navalesi P, Antonelli M, Valentini I, Melotti RM et al (2012) Effectiveness and predictors of success of noninvasive ventilation during $\mathrm{H} 1 \mathrm{~N} 1$ pandemics: a multicenter study. Minerva Anestesiol 78(12):1333-1340 
13. Zhou F, Yu T, Du R, Fan G, Liu Y, Liu Z et al (2020) Clinical course and risk factors for mortality of adult inpatients with COVID-19 in Wuhan, China: a retrospective cohort study. Lancet 395(10229):1054-1062

14. Alraddadi BM, Qushmaq I, Al-Hameed FM, Mandourah Y, Almekhlafi GA, Jose J et al (2019) Noninvasive ventilation in critically ill patients with the Middle East respiratory syndrome. Influenza Other Respi Viruses 13(4):382-390

15. Brochard L, Slutsky A, Pesenti A (2017) Mechanical ventilation to minimize progression of lung injury in acute respiratory failure. Am J Respir Crit Care Med 195(4):438-442

16. Esquinas Rodriguez AM, Papadakos PJ, Carron M, Cosentini R, Chiumello D (2013) Clinical review: helmet and non-invasive mechanical ventilation in critically ill patients. Crit Care 17(2):233
17. Leung CCH, Joynt GM, Gomersall CD, Wong WT, Lee A, Ling L et al (2019) Comparison of high-flow nasal cannula versus oxygen face mask for environmental bacterial contamination in critically ill pneumonia patients: a randomized controlled crossover trial. J Hosp Infect 101(1):84-87

18. Kelly BJ, Matthay MA (1993) Prevalence and severity of neurologic dysfunction in critically ill patients: influence on need for continued mechanical ventilation. Chest 104(6):1818-1824

Publisher's Note Springer Nature remains neutral with regard to jurisdictional claims in published maps and institutional affiliations. 